\title{
THE LIBRARY IN THE LIVES OF LATINO COLLEGE STUDENTS ${ }^{1}$
}

\author{
Denice Adkins ${ }^{2}$ and Lisa Hussey ${ }^{3}$
}

Libraries share a perception of embracing and providing for all users. However, they also share a common philosophical stance shaped by librarians' individual discursive formations and the dominant cultural hegemony that values some users over others. Latinos constitute one of the fastest-growing, nondominant populations in the United States, and the literature suggests that libraries do not always serve them adequately. This was reinforced by interviews with seven Latino undergraduate students that suggest ambiguous feelings toward libraries and a strong need for some sort of cultural reinforcement. This study of users' perceptions of libraries may help librarians and policy makers consider more pluralistic approaches to library services.

Introduction

When I was growing up, I remember not really having cultural books. Sometimes there'd be a cultural display, but it wasn't like a multicultural library. I think that would be just ideal . . . having books about every culture so that you don't just learn about your culture but you could go get a book and learn about somebody else's culture. But I haven't, you know, seen that. (Felicita)

I try to use [the university library], but it's just too confusing! . . . There's too much information, which is good, but I don't know how to use it, so I prefer not to. (Daniela)

1. A preliminary version of this article was presented at the Library Research Seminar III in Kansas City, MO, October 14, 2004.

2. Assistant professor, School of Information Science and Learning Technologies, 303 Townsend Hall, Columbia, MO 65211. Telephone 573-884-9804; Fax 573-884-4944; E-mail adkinsde@missouri.edu.

3. Assistant professor, School of Library, Archival, and Information Studies, 6190 Agronomy Road, Suite 301, Vancouver, BC V6T 1Z3, Canada. Telephone 604-822-2704; E-mail huss@ interchange.ubc.ca.

[Library Quarterly, vol. 76, no. 4, pp. 456-480]

(C) 2006 by The University of Chicago. All rights reserved. 0024-2519/2006/7604-0003\$10.00 
Libraries are considered by some to be a great tool of democracy, open to all regardless of race, gender, or creed [1]. These public institutions provide learning opportunities to all who choose to take advantage of them. The materials are there for anyone to access; individuals simply have to make the effort. And yet, therein lie both the greatest strength and weakness of libraries. At the most basic level, in order to use the library, one must first know how to read. Even in the United States, literacy is not universal. As a result, libraries actually "deny access to their resources to certain social classes" [2, p. 241]. Literacy is not limited to the English language, yet those who are literate in other languages are alienated because of a lack of resources or programs in those languages. In diverse communities, libraries are often limited by the extent to which they are able to deal with patrons' varied, and sometimes unknown, information needs. All of this leads to the questions of who is well served by libraries and who is left behind.

Latinos are one of the fastest growing populations in the United States, yet they are underrepresented in librarianship: the desperately small number of Latino librarians (4.6 percent of all librarians) cannot provide cultural reinforcement for the large number of potential Latino patrons (14.2 percent of the population according to the 2004 American Community Survey) $[3,4]$. Previous literature on Latino responses to libraries has suggested that Latino users distrust the library, feel insecure in interacting with library staff, and deliberately choose to patronize libraries in which they feel culturally validated. Unfortunately, recent studies of Latino response to libraries are limited; we found only one such study conducted after 2000 [5]. While we have factual data illustrating the patterns of Latino library use, we know little, as a profession, about how Latinos construct the meaning of library use and imbue significance to social interactions in the library. In order to serve this population effectively, it behooves us to know what the library experience means to them.

Three questions are explored in this project: Do Latinos feel alienated from the library as an institution? What do they think about the library and about librarians? Does the library serve a cultural role for Latinos? These questions are further examined within the framework of cultural hegemony and discursive formations. From this interaction, we suggest that library use is strongly mediated by cultural identity, though not necessarily by linguistic identity. The Latinos interviewed in this project do not represent the "typical" Latino. They are confident, goal-oriented college students who are experienced at navigating between their home culture and the dominant culture. They use the academic library, as befits their status, but they also use public libraries for personal reasons. Though the students represent only a very narrow subset of the Latino population, 
their perspectives provide an example of the cultural differences that may inhere in the nature of library experience for a nondominant culture.

Library Philosophy

While librarians produce policies and guidelines in order to help provide a uniform service to all library patrons, these practices do not always effectively reflect the needs of, nor benefit, the public and academic communities that they are intended to help. In order to understand what drives these practices and policies, it is important to understand the concepts of cultural hegemony and discursive formations and how they relate to the profession. Cultural hegemony is the creation and maintenance of a dominant culture by the ruling class that is accepted, either consciously or unconsciously, by the subordinate and/or oppressed classes through complicity and coercion [6, p. 574]. In other words, it is the process of providing and acknowledging accepted standards and policies in society based on one powerful group's idea of right and wrong, good and bad. As defined by Gramsci, the "ruling" class consisted of the bourgeoisie [6, p. 574]; in American society, this often translates to the rich or middle classes, generally with a white, Eurocentric point of view. This viewpoint does not automatically exclude minorities. However, it tends to define these groups as others, outside of the norm, and often relegated to the margins. Given this context, cultural hegemony is the means for providing accepted standards and policies in society based on one group's idea of right and wrong. This can be something as simple as setting business hours for an institution or as complicated as a hiring process. Both are structured and influenced by those in power. Although this definition simplifies the concept and the processes of a hegemonic culture, it does provide a starting point for examining the impact and implications within libraries as public institutions.

Along the same lines of the concept of cultural hegemony, discursive formations, as defined by Michel Foucault, provide a power base for the ruling class through the teaching of values and norms. Power, in this view, is not the traditional sense of "institutions and leaders, but the capillary modes of power that controls individuals and their knowledge, the mechanisms by which power reaches into the very grain of individuals, touches their bodies and inserts itself into their actions and attitudes, their discourses, learning processes and everyday lives" [7, par. 1]. This power base and structure manifests itself in the discourse and discursive practices in many public institutions, such as libraries. "Discourse is where everything that relates to power and knowledge . . . is buried" [7, par. 1]. In other words, our values and beliefs about power and power relationships are 
embedded in the actions we take and the language we use; we do not need to consciously articulate those values, for they are always with us. It is how a worldview is constructed based on where an individual is from, who raised her, the environment involved, and how this view is expressed. In other words, discursive formations provide the foundation for both individual and community values, as well as how each will view and discuss society and the people within it.

Discursive formations by definition deal with discourse. As a result, how we write and speak is also a reflection of our background influences. Within libraries, this can be seen in official communication, public statements, written policies, and in all forms of communication with the wider community or society. The language of communication, including words and meaning, are a larger reflection of the perceptions and expectations of the institution. How these are worded reflects how well the institution identifies with their service base.

Libraries are not simply storehouses of information; they are often also considered repositories of culture. They preserve information deemed important and provide access to that information. Each type of library has its own mission and goals, such as support for research, enrichment of education, or development of ideas. Public libraries are seen as being driven by the information needs of the patron base, while academic libraries are focused on educational needs of their patrons. Both types of libraries often have lofty goals aimed at meeting the needs of their communities. The language and the policies created by these goals often reflect a desire to work with the communities but are fashioned by those in power and so represent the prevailing cultural hegemony, limiting the influence of diverse discursive formations.

The influence of cultural hegemony is not limited to missions and goals. Librarians act as mediators between the patron and the information and, hence, interpret the information patrons need to meet the cultural expectations of the library. Librarians select what is included in the collection, which in turn influences what patrons are able to access and use. Ironically, many librarians do not perceive selection, preservation, or mediation as anything other than an impartial and unbiased process intended to assist individuals to find the best resources for their information needs. Yet, who decides what is "best"? Generally, it is the same person who decides what materials are the best for the library and what resources are the best for the community-the librarian [8]. Librarians are human. As a result, they are not neutral, unbiased individuals. Their individual values and backgrounds, the discursive formation from which each person builds his or her worldview, and the dominant cultural hegemony influence how a librarian will deal with each patron and how the library will present itself to the community. 
Libraries and professional organizations have put together documents and policies on information ethics and intellectual freedom in an attempt to broaden the professional perspective. While these are important policies and procedures, they still reinforce cultural hegemony as they are primarily written in the language of those in power. For example, statements on professional ethics are put together by professional organizations, the overwhelming majority of whose members are white. Intellectual freedom is influenced by the discursive formations of those who write and enforce these policies. It is those in power who decide what level of intellectual freedom the library will support.

Latinos' Perceptions of the Library

Most research on perceptions of the library tends to focus on evaluation of library services rather than discussing individuals' perceptions of the library. These studies center on whether or not students and faculty in academic libraries use certain services effectively. The perception of the library as a place, while not as prevalent, has presented some interesting findings. Jacqueline Kracker and Howard Polio tried to find "the way that libraries are experienced" in order to understand "what library patrons might want or need in the way of library services" [9, p. 1106]. The respondents were encouraged to describe any experience in a library, regardless of the type of library. While these responses varied, some common themes emerged: atmosphere, size and abundance, organization and rules, uses of the library, and memories. The authors concluded that one's experience of the library changes over time, especially when comparing school and public libraries with academic libraries. They did not address issues of cultural needs, and as the focus was on the general undergraduate experience, they did not include ethnic demographic data.

What do Latinos think about libraries and library services? While research soliciting user attitudes toward libraries is not thick on the ground, we identified several studies that attempt to answer this question. Spanning a period of thirty-five years, these suggest that Latino users are looking for cultural and linguistic reinforcement; educational support, including study space; a space free of value judgments and in which Latinos can express their opinions; and a space in which they can learn about those elements of their culture that conflict with the established order (e.g., the Brown Berets, a Chicano militant group of the 1960s and 1970s, or dealing with California's Proposition 187, a bill to deny public benefits to immigrants). These general desires are consistently reported, irrespective of time period, method used to collect data, or library type (public or academic).

During the Latino activist movement of the late 1960s, Roberto Haro 
presented himself as a cultural insider in order to conduct interviews with "approximately six hundred Mexican-Americans in East Los Angeles and Sacramento" [10, p. 736]. His study looked at multiple library types (school, public, and college), though the distribution of users of each library type was uneven. Only 9 percent of his respondents had used college libraries, compared with 65 percent who had used school libraries. Haro's discussion of college libraries is proportionate to the small number of users with whom he spoke. Nonetheless, he notes that Mexican American college library users were willing and eager to share their ideas for improving library services. "Seventy-seven percent of the students interviewed believed that ordering more library materials was not the answer to their needs" $[10$, p. 742$]$. The problem was not merely that information sources were not available but that the library did not acknowledge nor respond to their cultural differences. In this way, the library reflected the prevailing cultural hegemony rather than the discursive formations of the community. Haro's students wanted to see revised service policies, more courses on how to use the library, and the establishment of specialized, separate reading areas for ethnic studies.

The willingness of Haro's Mexican American college students to discuss change is exceptional. Of his 600 respondents, while 17 percent were unhappy with library services, 77 percent said they did not care about library services. Mexican American parents did not know how to influence the educational system to obtain quality school libraries for their children, while public library users were mistrustful of that "Gringo middle class institution" [10, p. 740]. Haro's public library users wanted, but rarely received, space for after-school group work, cultural programming, and culturally responsive collections. The public library failed to utilize Spanishlanguage media to advertise its presence and failed to provide the cultural reinforcement desired by the Mexican American population.

In his relatively brief 1970 article, Haro does not elaborate on his data interpretation process, nor does he provide much information about the population he selected for his interviews, except to say that he eliminated 400 respondents to provide an accurate sampling. His interviewing method was "as unstructured as it could be" [10, p. 737], and though his approach was interpersonal, his results are quantitative. In another project undertaken between 1970 and 1972, he used structured interviews with 2,917 users and nonusers, including 285 students [11, pp. 3-17]. Of those surveyed, only 751 (26 percent) were library users. Major reasons for nonuse were a lack of awareness of the library and what it had to offer and transportation issues. Of those who did use the library, over half had learned about the library while they attended K-12 schools. The primary uses made of the library were borrowing materials and books and getting job-related information, though users expressed a need for more Spanish-language 
and culturally relevant collections. Neither users nor nonusers saw libraries as a place for social gathering. Almost one-fifth of nonusers said that going to the library made them uneasy. Nonusers had a high level of print and Spanish-language media awareness but spent their free time gathering with family and friends, watching movies and television, or participating in church-related functions [11, pp. C16-C17].

The method used for the user-nonuser questionnaire was a door-to-door survey of houses in predominantly Hispanic areas. These areas were selected on the advice of a real estate agent familiar with the city in question. Over half of Haro's survey respondents were women, and many of those women were housewives, a rate that may be biased by the days and times this survey was conducted. Haro notes that more respondents were probably inclined to say they were users than actually were. The survey instrument was composed of closed-ended questions with little opportunity for individualized feedback. The survey was also oriented toward public libraries, for the most part excluding college libraries.

Between 1976 and 1979, Haro supplemented his survey results with observation data from ten of the previously studied metropolitan areas [12, p. 93]. He focused on several themes that dissuaded Latinos from using libraries in these ten cities: a lack of awareness of library services, a lack of culturally relevant materials at the library, perceptions and instances of racism on the part of librarians, and an inability to communicate with monolingual library staff [12, pp. 93-99]. The results again reflect the influence of cultural hegemony on the library as members of the community do not see their own views and needs reflected in the institution. Haro presents his 1981 results in a more qualitative structure, using extensive quotes to describe the needs of his Mexican American respondents, and, in an appendix describing a methodology for user studies, he discusses the impact of the investigator's biases on the potential research [12, p. 280].

In 1984, Salvador Güereña reviewed the results of five unpublished library surveys of Latinos in California [13]. Studies were conducted for the San Jose Public Library (1975), Richmond Public Library (1976), San Bernardino Public Library (1977), San Diego Public Library (1978), and Santa Barbara Public Library (1980). The method used for all of these studies was the household survey using a bilingual questionnaire. Latino neighborhoods and households were identified using census data and random or cluster sampling methods. These five studies (together) reached over 1,400 Latino residents in California. Reasons given for not using the library included a lack of awareness of library services, a lack of linguistic relevance, or a lack of personal significance for the potential user. One study suggested that the library was viewed as an educational resource for children and students, though another indicated that the primary use of the 
library for Latino adults was to check out leisure materials. According to Güereña's summary, a surprisingly large percentage of respondents were women and older people-possibly the result of men and young people being outside the home for work or school.

The Latino empowerment movement became less prominent in the 1980 s, but the release of data from the 1990 census directed attention to the American Latino population once again. The Hispanic growth rate of 53 percent significantly overshadowed the white population's growth rate of 6 percent [14]. This dramatic increase prompted a study of aggregate public library services to Latinos, which was published in 1994 as the Report Card on Public Library Services to the Latino Community [15]. The Report Card, compiled by Reynaldo Ayala and Marta Stiefel Ayala, articulated indicators of Latino library services and measured libraries' success in meeting those indicators. In addition, using a survey instrument that asked the respondent to assess the library's performance using a four-point Likert-type scale (with an additional option for "I do not know/No opinion"), they gathered user feedback on how well they thought their libraries met the indicators. Respondents' answers to survey questions indicated that libraries needed to provide more Spanish-language periodicals, bilingual forms and signs, bilingual staff and professionals, and cultural and educational programming. Survey results were reinforced by written comments suggesting a greater need for culturally relevant materials, approachable bilingual staff, stronger outreach to the community, and larger buildings in better repair. Despite these needs, a large percentage of users said that the library made a difference in their lives and that they would recommend the library to a friend.

The Ayalas sent the National Users' Satisfaction Survey to 351 Latino library patrons from 104 public libraries and received 81 responses (23 percent response rate) from fourteen states. This response rate is in line with other mail-back surveys in which "response rates . . . tend to be between $10 \%$ and 50\%" when incentives and reminders are not included in the survey design [16, p. 119]. In their discussion of limitations, the Ayalas admit that allotting more time and attention to the user survey might have improved the response rate. Approximately 60 percent of respondents were female, and over 50 percent identified themselves as either library users or parents [15, pp. 102-3, 107-8]. Users receiving surveys were selected by their libraries; however, the survey and cover letter were identified as coming from REFORMA rather than the library, and users may not have connected the surveys to their library use.

A qualitative research project provided some degree of insight as to the experiences of Latino users of the Santa Ana Public Library [5]. Susan Luévano-Molina conducted ethnographic interviews with fifty Latino and Latina immigrants and was particularly interested to learn if their perceptions of the library had been affected by the prior passage two years earlier 
of anti-immigrant legislation. These users, "typically young, primarily lowincome, and working class," predominantly spoke Spanish and preferred to use Spanish in their interviews and in their library use [5, p. 49]. Respondents spoke of the library as contributing to a sense of community. They felt that the library was a "neutral space" that did not discriminate against users and in which they were "interconnected to the existing social order" [5, p. 57]. They regarded the Santa Ana Public Library in particular as a place that had excellent collections and staff [5, p. 58]. Positive attitudes did not always translate into library use, however. "The majority of the participants had very positive impressions of the city library system even though half of the participants had never entered a public library or bookmobile" [5, p. 50]. Participants may have been reflecting their view that library use is a good thing that ought to be supported for the benefit of others, even though they did not use it personally. Haro's survey participants also expressed this idea.

The ethnographic interview method allowed Luévano-Molina to map the meaning of library use along a political and cultural dimension for her Latino immigrant users. Interviews were conducted in the users' comfort zones, at home or at community gathering places, and the snowball sampling technique suggests that at least half of the respondents were part of the same social network. Luévano-Molina acknowledges that her study is not consistent with other studies that indicate Latinos are not aware of and do not esteem the public library. As her focus is limited to a community with a remarkably proactive library, her research participants are necessarily different from participants in other studies. Additionally, the juxtaposition of public library availability and anti-immigrant legislation may have deterred participants from fully describing their attitudes toward public libraries.

While a limited number of studies focus exclusively on Latino library perceptions, Ethelene Whitmire has authored several quantitative studies looking at the academic library experiences of students of color generally. In one such study, her subjects were the 9,327 undergraduates who had completed the College Student Experiences Questionnaire in 1996, of whom 3.6 percent were Latino. Students estimated the frequency with which they performed various types of library use, such as using the library to study, using the catalog, checking out books, or asking the librarian for help. Perceived usage rates were similar for respondents from all ethnic groups [17, pp. 153-58]. However, some factors influenced academic library use among Latino students, including increases in course learning activities, writing experiences, and the number of nonassigned books read [17, p. 160]. A subsequent study used responses to an undergraduate student satisfaction survey to determine whether perceptions of the campus racial climate would influence perceptions of the academic library [18]. 
Whitmire's comparison groups were white students and students of color, inclusive of Latinos. Perceptions both of campus racial climate and the academic library were not significantly different between these student groups.

Whitmire's quantitative research projects have demonstrated that factors motivating library use differ between racial groups. Her instruments allow her to generalize her conclusions to a larger body of students and to compare attitudes and behaviors between ethnic and racial groups. However, the grouping of "Latinos" together may be misleading, particularly in the college environment. The sample sizes of Latino subgroups (e.g., recent immigrants, native born, Mexican American, Cuban American) are too small to allow for meaningful cross-cultural comparison in a situation in which there may be noticeable differences between students from one background and students from another. Further, the nature of the instrument limits Whitmire's conclusions to descriptions of students' attitudes and behaviors rather than true understanding of the conditions that motivate them. She suggests the use of qualitative methods to enable researchers to "really 'hear' the voices of the students of color describing their academic library experiences" [18, p. 374].

These studies were the only ones that we identified that looked specifically at Latino user perspectives and desires over this thirty-five-year period. It is worth noting that all of these studies were authored by people of color, and most of them were conducted by Latinos. The research also suggests a Western bias. Haro, Güereña, Luévano-Molina, and the Ayalas all resided in California when their studies were published. The authors all come from postsecondary environments. Haro, both the Ayalas, and Whitmire hold doctoral degrees. Haro and Whitmire have both taught in LIS education programs (Whitmire recently, Haro in the 1960s); Haro and Reynaldo Ayala both taught outside of LIS as well. Haro, Güereña, LuévanoMolina, and Marta Stiefel Ayala worked in academic libraries. Latino researchers who have been confronted with library usability issues during their own academic studies are likely to have a different way of thinking about libraries than their white, monolingual English-speaking counterparts. Doubtless, each of the studies was influenced by the authors' ethnic or racial backgrounds and the social networks these authors occupied, while their publication and national availability are a result of the academic imperative to share research findings.

The influence of these studies on the field of LIS has been generally limited to practitioners. Haro's 1970 study was the first to address the library from the viewpoint of the Latino user and one of the first articles about Latino library service to receive national distribution in a popular LIS periodical. A search of the Social Science Citation Index (SSCI) reveals that Haro's 1970 article was cited only twice between 1970 and 1975, and 
never since. But SSCI indexes only periodical literature; if citations are evidence of influence, Haro's article does in fact wield some influence in practitioner publications. ${ }^{4}$ Haro's user studies of the 1970 s provided the foundation for books and service manuals in the 1980s and 1990s that described how librarians ought to serve the Latino population. The Ayalas' Report Card is another example of the lack of visibility of Latino user studies. Released to great fanfare in 1994, it has largely been ignored since. Since its 1994 release, it has been cited once per SSCI and is not indexed in Library Literature, Information Science and Technology Abstracts, or even in the ERIC database. To the librarians who serve Latino populations, however, this report was critical in establishing a rationale for improved library services. ${ }^{5}$ Even in the early twenty-first century, a considerable portion of the literature on Latino library service appears in service manuals, monographs, or conference proceedings, as with Luévano-Molina's chapter. These works generally have less visibility than peer-reviewed articles published in LIS journals and can be harder to track without additional knowledge of the Latino library service literature.

\section{Method}

To learn more about the significance of library use for Latinos, we conducted semistructured interviews with seven Latino college students in the summer of 2002 at a large university in the southwestern United States. Methods previously used to analyze Latinos' library use include quantitative interviews, surveys, and ethnographic interviews. The quantitative interview is an effective way to establish patterns of use and nonuse over a large population, but it limits the potential for exploring issues such as individualized experience. The survey method allows the researchers to specifically target the Latino library-using audience but also limits the potential for exploration of meaning and does not achieve the high response rate of the quantitative interview. The participation rate for ethnographic interviews is necessarily smaller than for quantitative methods, and representativeness cannot be ensured. However, the depth of analysis of participants' information compensates for the comparatively small number of participants. Our study posed particular difficulties in observing participants in the desired context: there was no guarantee that Latino patrons

4. The 1970 article is cited in at least four book chapters that the authors can readily identify: Roberto Cabello-Argandoña [19]; Bruce Jensen [20]; Salvador Güereña [21]; Sandra Pucci [22].

5. This study is also cited in at least one recent book by Camila Alira and Orlando Archibeque [23]. 
would be in the library at any given time, nor was there any guarantee that we could identify Latino library users based on appearance alone. Further, because we were interested in learning about the meaning of library use, we could not use a survey or questionnaire to test concepts that might differ among participants. Following Luévano-Molina's example, qualitative interviewing seemed a reasonable compromise between these two positions.

Students were recruited by means of an e-mail message sent to the university's Latino Student Services mailing list, which meant that students reached by this invitation were those who were publicly identified as Latino and willing to participate in the activities of the Latino Student Services center. As such, they may have been more active and passionate about their ethnic heritage than Latino students who were not subscribers to the Latino Student Services mailing list. Because the invitation was for an inperson interview, and because the invitation was sent in the summer, the population reached was potentially much smaller than the total pool of Latino students who attend the university. The students who did respond were likely to be taking summer classes or otherwise engaged in scholarly activity over the summer. This suggests that the participants may have been more committed to academic activities than the typical Latino student. Indeed, one participant was involved in a summer program designed to introduce new students to the university at a time when it was less crowded and when they could get more personal attention from instructors.

The first author interviewed all seven participants (who were given a $\$ 10$ cash incentive), and each session lasted approximately forty-five to sixty-five minutes. The establishment of rapport between interviewer and participants is a recognized and desired component of qualitative research. Cultural bonding between participants and interviewer was limited in our study, however, due to the fact that, even though the interviewer is of Mexican American heritage, she is not visibly Latina. While participants and the interviewer shared ethnic heritage, the student participants could not assume that shared heritage. Six of the seven participants were women; the interview with the male participant was the most concise of all the interviews. So, perhaps the female participants and interviewer were able to share some gender-based rapport even without the cultural bond. National statistics indicate that 57 percent of Latino college students enrolled in 2002 were female [24, p. 172]. However, the large number of women responding to the current study suggests that Latina college women may be more involved in summer studies or more responsive to library-related issues. Techniques such as active listening and restating of participants' contributions may have helped broaden this connection.

Interviews were conducted in an office space that was convenient to the interviewer, but it was not located near the university library, and it was 
not familiar to the students. The potential for participant observation in the library setting was lost, but students may have been more comfortable discussing the library when they were not in the library building itself. However, because the setting was unfamiliar to the students, they may have been less at ease than if the interviews had been conducted in a familiar space such as the Latino Student Center or the Student Union.

To maintain consistency while allowing the participants to describe their own motivations, the interviews were semistructured, and questions were open ended. Although much of the conversation was driven by individual answers, we developed an interview guide based on themes emerging from previous studies of Latino library users. This guide was reviewed for content by a non-Latino librarian and, after review, was used as a general starting point for the interviews. Interviews were tape-recorded and transcribed, and these transcripts were used for the research process. Questions in the interview guide included the following:

- Which libraries do you visit on a regular basis?

- When you go to the library, can you find what you are looking for without assistance?

- What do you think about the people who work at the library? Is there anyone at the library that you particularly like working with?

- Have you worked with many librarians who could speak Spanish?

- Do you consider yourself a reader?

After transcription, the information provided by participants was organized by topic and then categorized by the first author based on themes extracted from previous research on Latinos' views of libraries. The ethnic and educational background of the first author allowed her to interpret participants' descriptions of their thoughts and actions within the appropriate cultural framework. The second author, while not sharing the ethnic identity of the participants, has made a particular study of contemporary philosophy. When she read the results, she connected them to theories of cultural hegemony and discursive formations. Both authors have been immersed in previous literature on the library use of ethnically diverse patrons. By combining their strengths in this research project, they have attempted to balance the results between analysis of participants' views of library use and broader contextualization of their experiences in libraries. Additionally, each author served to enlighten the other as to her predispositions and biases and how those might affect the interpretation of results.

Of course, these students do not represent the whole of the collegegoing Latino population, and they represent the entire Latino population much less. In 2002, only 8.1 percent of Latinos ages 25 and over held bachelor's degrees, compared with 17.7 percent of the total U.S. popu- 
lation [25, p. 154]. This suggests that these students are likely to be in the process of developing a different discursive formation than the majority of Latinos. Their worldview, while undoubtedly still influenced by their ethnic background, is also likely to incorporate the concepts and ideals of the college-educated dominant class.

Due to the limitations of the research situation, the number of participants was much smaller than we had anticipated. Though the study was limited to Latino university students, it seems very probable that there are Latino students with other experiences of the library whose views are not represented by these seven students. Perhaps if the sample had been expanded to include students who were not enrolled during summer session or those who were less actively aware of their ethnic heritage, the experiences reported would have been very different than the ones recorded here. With such a small sample size, some views may not be represented, and others may be overrepresented.

\section{Findings}

All seven students interviewed had high career aspirations and viewed education as the necessary path to achieving those aspirations. Though all students were fluent in English, they were not all fluent in Spanish. This may be a sign of linguistic assimilation; in the United States, immigrants' bilingual skills are typically lost within three generations [26, p. 319]. The students, whose names have been changed, are described below.

- Alicia was a freshman taking her first course through a program designed to help minority and underprivileged students make an effective transition from high school to college. Her career goal was to graduate from medical school and work as a pediatrician. Alicia lived with her parents in a relatively prestigious area of town, and her boyfriend was also in the premed track.

- Berta was a junior, majoring in psychology. She had been to counseling after a trauma and was so inspired by the assistance she received that she decided to pursue counseling as a career. Berta was close to her family but felt that they had not provided much support for her educational goals. She lived off campus with her boyfriend.

- Carlos, a husband and father, was in his junior year of a psychology degree. A nontraditional student, he came to the university well after graduating from high school. Although he had a successful previous career in business, he gave that up to follow a family member into medical school. He took his first years of course work at an out-of-state university and moved to have better access to medical resources. 
- Daniela was a sophomore intending to transfer into the physiology department. Prior to attending the university, she had attended local Catholic schools and, with a group of other young Latinas, had celebrated her quinceañera (a fifteenth birthday celebration of a girl's coming of age, frequently celebrated with a Catholic mass during the day and a formal party at night). She had strong family and community ties and lived with her parents.

- Elena was a junior with a double major in ethnic studies and political science. "I don't see myself just as a Mexican American," she said. "I come from a lower social class, so I kind of see that as my community as well." Her goal was to finish law school and go on to work for a nonprofit agency and try to build a society more accepting of difference. Elena lived on campus and was involved in the prelaw fraternal organization as well as several book discussion groups; she also held a parttime internship with a law enforcement agency.

- Felicita was a senior majoring in elementary education. She wanted to be an elementary school teacher after graduation but planned to return to the university to earn an advanced degree and move into school administration. She was employed in the local school system to reach out to low income and minority students to encourage them to go to college. During her first year at the university, she had participated in the same program in which Alicia was currently enrolled. She had come from another city, and her family still lived there; she lived on campus.

- Graciela had just graduated from her undergraduate program and was planning to pursue graduate studies in public health in the fall. She had originally planned to attend medical school and become a doctor but realized she could do more to provide equitable access to health care as a health care administrator than as a doctor. Her family had emigrated from Central America when she was a young girl. Prior to attending the university, her classmates and neighbors were mostly white. She found the local environment to be oriented toward Mexican Americans to the exclusion of other Latinos.

The students' focus in responding to interview questions was the university library system, which all had used. Five of the students referred to public libraries as well, while three shared memories of their school library experiences. Academic and public libraries served clearly different purposes for these students. Students' information needs were shaped both by their educational goals and by their culture. Their information needs are mitigated by their library perceptions: the academic library is primarily used to support course work, while the public library is used for cultural support. In the paragraphs below, we look at each of the research questions, identifying cultural nuances that may have affected these students' feelings 
toward the library and suggesting some ways in which the dominant cultural hegemony comes into conflict with other cultural values.

Do Latinos Feel Alienated from the Library?

Despite studies from the 1970s that indicated a significant degree of discomfort among Latino library users, these Latino college students tend to support Whitmire's findings that students of color do not necessarily feel alienated from the library. When questioned directly, none of the students claimed to feel discriminated against or unwelcome in the academic or public libraries. "None of them [librarians] have been discourteous in a really rude way to me," said Elena, who also admitted, "Some of them are nicer than others." Deeper analysis of the students' responses suggested that the Latino students' attitudes toward the academic library were associated with their comfort level within that library. Students who felt confident in their informational and spatial navigation skills (those who seemed comfortable) had positive attitudes about library services and librarians. By contrast, those who were uncomfortable in the library seemed to be more judgmental about library services and provisions. Examples in the paragraph below illustrate this point.

Students' facility in academic library navigation was revealed through their descriptions of library interactions and seemed to be influenced both by their experience and training in library use and by the perceptions they had of the library building. Felicita and Carlos had had formal introductions to library resources, as well as having librarians visit their classes to talk about library research. Graciela and Elena had only library class visits. Alicia, Berta, and Daniela had not had any formal library skills training. The students who had some degree of orientation to the library were comfortable using the academic library and spoke more positively about it than those who had not. For example, Felicita's formal introduction to library resources made her "comfortable" using the online public access catalog, using books, and speaking to staff members. She described her experience with formal library skills training: "We actually went on a library scavenger hunt. . . . It wasn't thorough, but it was good enough to get through. [Library staff] were there if we needed to ask questions. . . . Obviously I'm a senior now, so it's not as intimidating as if I were a freshman again. But I do remember when it was this big huge thing, and I knew that I could ask questions if I needed to." Felicita said she was somewhat uneasy using library resources with which she was unfamiliar, such as microfiche. On the whole, though, she called libraries "valuable resources" and planned to incorporate library use into her teaching career.

Graciela's academic library skills training had been limited to librarians visiting two of her classes to model online search strategies. She spoke confidently of her abilities to find information online but was ambivalent 
toward the physical library building. She described her information-seeking strategy: "If I don't [find appropriate materials in the library], I'll just use the Internet as a source and that'll usually help me out. . . . You can use the [library databases] from anywhere on campus, instead of having to go over there." Though Graciela spoke positively of her ability to navigate the academic library building, she preferred not to have to do so. However, she was comfortable in, and enjoyed using, the specialized health sciences library. Navigating that library, she said, was "very simple, . . . very easy to find things there."

Daniela had no library skills training. Describing her transactions at the university library, she consistently used negative language. "I hate the university library! . . . You have no idea where anything is . . . I don't know how to use it." She said that the university library "scares" her, and she called it, "overwhelming." Daniela preferred to use the public library, focusing her explanation of this on the public library's organizational features: "I know where everything is! . . . You know, they have the information bulletin [that says] 'this floor for this, this floor for that,' and it's really easy to find things." A smaller building, with a smaller collection, made the public library less daunting than the large university library with its collection spread throughout several buildings, each comprising several floors.

Daniela's increased comfort level at the public library was not unique. Several of the students had more positive attitudes toward the smaller public library than they did to the large university library. Graciela, who had expressed ambivalence about the university main library, reinforced that ambivalence with her comments about library size: "The [university's] main library is so big, you could get lost in there, you know, with all those books. When you were younger, it was so simple, you looked at the nonfiction versus the fiction . . you could just go into the aisle and there were all those books, not necessarily by a number but by a section." The size of the library contributed to the Latino students' comfort levels. In general, the larger the library and the more complex the systems of information retrieval, the less comfortable the students felt in that library.

While our Latino participants did not feel actively alienated by libraries, not all of them were comfortable in large, impersonal libraries such as the university library. Looking at these results from the perspective of cultural hegemony suggests that students' awareness and acceptance of the academic library's prevailing hegemony may have helped these students understand their role and responsibility in academic library usage. Users who are not from the dominant culture will feel less comfortable in an institution of the dominant culture. However, those Latino students who had received training understood the accepted uses of the academic library and worked within those parameters. Haro's 1970 publication indicated that 
students have a strong desire to learn how to navigate library resources. For students from a nondominant culture, knowing how to use library resources is not merely about finding information but also about navigating culture.

Not surprisingly, to these students, smaller settings such as school and public libraries seemed to provide more intuitive services. School and public libraries are often able to reflect the community to some degree, providing a more culturally responsive service. These smaller, communityoriented libraries are more likely to identify power brokers as closer to home. Even these libraries might benefit from an active awareness of their discursive formations to continue actively and knowingly providing relevant services.

What Do These Latino Students Think about Libraries?

In previous studies, Latinos were documented as viewing academic and public libraries primarily as educational tools. As befits a culture with a strong respect for education, the Latino students in our study continued to approach the academic library from a study-centered orientation. Most of the students had very definite ideas about appropriate library behavior and the appropriate uses of the university library building. The academic library building was viewed as a source for information, a place for quiet study, and, to a much lesser degree, a place for "social" study.

Despite their educational focus for academic libraries, they approached the public library with a more social orientation. They had more positive attitudes toward social activity at the public library, and two students spoke of positive interactions with public library employees. Some of the students had been involved in social reading activities through their public libraries. Within the last year, Elena had participated in three book discussion groups at the public library. Alicia noted that authors and guest speakers appeared at her local public library. Daniela, Elena, and Felicita said they participated in summer reading programs as children. Because of these social activities, public libraries seemed to have different purposes for these students than did academic libraries. The academic library existed to facilitate schoolwork, while the public library was a community resource much like a park or a museum.

Beyond seeing library size as influencing their comfort levels, students used it as an indicator of informative potential. Larger libraries were seen as containing more information. Felicita talked about her high school years when she felt her information sources were extremely limited. "Our [school] library was sort of small, and we didn't have a big public library." She used the size of the library as an indicator of the amount of information it can provide. Likewise, Daniela thought more books suggested more information. Her self-professed hatred of the university library did not extend to the health sciences library: "I walked in, and it was the most 
amazing library I'd ever seen. It was just books and books, rows of books. I was, like, 'Oooh, I can have any resource I want at my disposal when I get to med school!"” The perception of unlimited subject-specific information was empowering for Daniela.

Regardless of the information potential seen in large buildings full of books, most of the students also regarded computers and the Internet as prime information sources. At the time of the interviews, a large computer lab had been added to the library. Reactions supported the idea that computers increase the information capacity of the library, as well as increase the social nature of the library. The excessive size of the computer lab did not seem to have the same negative effect as the excessive size of the rest of the university library. While students thought a large library was confusing, they were empowered by the large computer lab. Unlike other aspects of library services, computers provided access to information without direct mediation of a librarian or other staff.

The students linked the ideas of computers and information and spoke positively about the potential for computers to inform. Alicia said, "There's a lot of information on the computers, and there [are] always available computers" in the new facility. Felicita suggested that accessing information on computers seemed easier than using traditional, non-technology-based means. "When I was a kid growing up, we had to do, you know, looking through the card catalog for things. Now everything's on computer, which is a lot easier." To these students, computers and books were both familiar, but computers were surrounded by a mystique: computers made information easy.

When considering the social aspect of the new computer lab, the students voiced some ambivalence. While the idea of an academic library suggested solitude and quiet study, the presence of computers suggested a common area for noisier interaction. Felicita and Elena spoke about the value of cooperative learning and group work and said that they appreciated that the lab enabled group work. However, some of the other students said their use of the library as a quiet study place was compromised by students doing group work and by the "computer noise, clattering and click-clickclick." Negative comments also suggested a discontinuity between students' perceptions of library space and computer lab space. Two students suggested that the academic library was not the appropriate place for such a major computer area.

These students associated both public and academic libraries with books and books and computers with information. They associated academic libraries with studying and public libraries with social or recreational reading. However, their associations may not be representative of the larger Latino population, particularly with regard to linguistic needs. Unlike the respondents to previous surveys, all of the Latino student participants in 
this study were fluent in English. Language was not a barrier to their success. These students have spent years learning to navigate between their own ethnolinguistic culture and the dominant American culture, and their persistence in postsecondary education is a sign that they have done so successfully. Latinos who do not maneuver between cultures so fluidly may not be able to adapt so quickly to academic and public libraries' discursive formations.

\section{What Do These Latino Students Think about Librarians?}

Despite students' strong opinions of the library building and the information resources available therein, their opinions of library staff were much less pronounced. The seven students tended to echo Graciela, saying, "Most of the people there are very nice, they're very helpful." However, when the subject was pursued, students had difficulty remembering specific interactions with library staff. Students' disinclination could be due to very limited interactions with library staff; an inclination to see library staff as "other," either in terms of age or ethnicity; or it could have been due to a reluctance to speak negatively of library staff with the interviewer, who had positioned herself as being connected to libraries in general. The students did not seem to differentiate between librarians and paraprofessionals. The main distinction between staff at the academic library was between adult librarians and student workers. At the public and school libraries, most people were referred to by the generic term "librarian."

When asked about contact with academic library staff, none of the students indicated that they had experienced overt racism, but neither did they have memorable interactions with academic library staff. One indicated some level of discomfort with student workers at the library, saying that student workers had difficulty understanding her and effectively translating her information needs to library resources. However, the students' interactions with academic librarians seemed fairly limited. The most commonly reported experience was class visits from librarians who explained how to use various information resources; four students recalled this. Interactions mentioned by one student each included retrieving a book from a reserve desk attendant, being shown how to use information sources in a library instruction program, and being approached by a roving reference staff person. Perceptions of the library instruction program and the roving reference approach were positive. "They started having people go around and ask if you have a question, but at first [during her first few years at the university] they didn't, and I'd be embarrassed to ask a question," said Graciela.

Likewise, no student recalled a bad experience at the public library, and two specifically mentioned their school library experiences as being positive. Elena had a very positive experience with a Latina librarian at the 
public library. Another positive experience involved Daniela desperately seeking a poetry resource but being unable to find it. The public library staff person with whom she worked found it easily and wrote down the Web address so that Daniela could access it at home.

Students had little experience with ethnic library staff. When questioned directly, none of the students could recall interacting with Spanish-speaking academic library staff. This was despite the fact that, at the time of the interviews, at least three people on university library staff were of Latino heritage. In fact, only two of the students had any experience with Spanishspeaking librarians. Felicita noted a Spanish-speaking librarian at one of the middle schools she visited for her job. Elena had participated in a book discussion group led by a Latina librarian. "Oh, Sara the librarian, she's really cool," said Elena. "She's one of the people I always look for first because I'm familiar with her. She's always willing to help."

Many students noted this level of helpfulness and enthusiasm when they discussed their ideal librarian. Every student mentioned that a good library staff member ought to be friendly, approachable, and dedicated to helping people. By contrast, only three mentioned that the ideal librarian ought to be knowledgeable about information resources, and only three mentioned that the ideal librarian ought to have skills in a second language. This suggests that these students were seeking personal connections and positive interactions as much as (if not more than) information transactions. Further, as all students were fully fluent in English, Spanish language reinforcement may have been less necessary for these students than for other Latinos.

Does the Library Serve a Cultural Purpose for Latinos?

The students regarded both academic and public libraries as sources of general information. However, the academic library was dismissed as a source of cultural reinforcement. "Most of the writing, most of the publications are usually relatively ethnocentric, you know, European American culture based," said Berta. When they discussed libraries that did present cultural information, students mentioned public or school libraries. Felicita, who volunteered at a local school, said that the school library had "Leer" posters ("Read" posters in Spanish translation) and Spanish books. "I think that makes a difference. When I was growing up, I remember not really having cultural books. Sometimes there'd be a cultural display, but it wasn't a multicultural library." Daniela noted that the public library's children's room had "a little section dedicated to Mexican American month or even Native Americans." Elena said that she found books by Latino authors when she worked as a library shelver in eighth grade, and, more recently, she was involved in an ethnic book discussion group. "On a scale of 1 to 5, how [Latinos are] represented, I'd say we're maybe 
a 3. Somewhere in the middle. Maybe not to the full extent that we should be, but we're there." These students acknowledged public and school libraries, not the academic library, as providers of cultural diversity.

Academic libraries were also dismissed as providing entertainment. Felicita, commenting on the academic library, said, "I haven't gone and gotten things just for personal use. I guess to me it seems like it's just for the classes. It's not, like, something you would just kind of go to, with the desk and requesting and everything." Elena echoed these sentiments, saying, "Right now I'm reading something for class, but I wouldn't consider that reading." Her implication is that, for her, reading for pleasure and reading for information are separate acts. Public libraries were used to seek out personal reading and leisure entertainment, and this personal reading was frequently culturally motivated. The students were very interested in materials reflecting their cultural heritage. As with previous studies that indicate a thirst for current events, several of our participants maintained a broad worldview and read a wide variety of periodicals. Elena mentioned reading the newspaper daily and discussed several books she was currently reading, some of which she had picked up at the public library's Latino book discussion meetings: "Sometimes I pick up books, and I feel so bad because I'll pick up five books at once, and I can't read them all at once. That's one of the things that really gets to me, because [one book] I've had for two weeks, and it's time I cracked it open, but then I'll look at Demetria [a book by Demetria Martinez] and say, 'oh, this one's flowing so well!' So I do consider myself an avid reader, especially when I have time to do so. During the summer I read a lot more than in the school year." Carlos also named multiple books and periodicals he was reading based on his interests. "I'm still going on this Aztec thing from two semesters ago [a course he had taken]," he said. Graciela said that she loved to read in Spanish. In contrast, Elena was frustrated at being unable to access translations of books written in Spanish, because English was her first language. Graciela and Elena both noted that they had limited opportunity for reading during the school year. It may be that these students use reading as a way of maintaining connections with their Latino culture while participating in the larger culture of the dominant society.

Reading seems to allow these students to explore and reinforce their cultural heritage, and they speak of public libraries as being more culturally relevant and responsive than academic libraries. After the students were initiated into the academic library's discursive formations through bibliographic instruction, they felt more comfortable in the academic library and better able to find information for classes. Despite the depth of informational resources, however, they could not recognize how to access personally or culturally relevant information in the academic library. The academic library limited the students by providing training that was nar- 
rowly focused on how the user fit within the context of the library, and how the library fit within the context of the university, rather than acknowledging how the library fits within the context of the users' education and life. The public library, however, acknowledged cultural differences and provided some resources for cultural exploration. Taxpayer funding and a more holistic view of the public library's role within society places more emphasis on the user as a member of a larger society and the library's context as one of many services available to users.

\section{Conclusion}

This study used a deductive model to extrapolate the meaning of libraries and library use for a small group of Latino students attending a major university. The purpose was to discover if feelings of alienation existed, the cultural purpose of libraries and library use for Latinos, and the perception of library and librarians by Latinos. We found that students' feelings about the academic library were complex and nuanced. While the students displayed some signs of alienation from the library, these negative feelings were mitigated by some positive impressions and experiences of library services as well as of individual librarians. The students also showed a clear comprehension of (and, to some extent, shared) the libraries' discursive formations. For these students, academic library use is primarily motivated by informational need, and comfort in the academic library is a function of their knowledge of library norms. Public library use was more frequently motivated by a desire for cultural reinforcement or a desire for entertainment materials (which may also help reinforce culture). However, library use was never motivated by an overt need to socialize. Students understood libraries as sources of books and information, but (except in special instances such as when working with bicultural staff) library staff have relatively little importance for these Latino students. For several of these students, reading was one strategy they used to deepen their understanding of culture. These students seemed to use academic libraries as strategic tools for navigating the dominant culture, while using public libraries required less concerted effort due to their differing community responses.

As the study shows, libraries' discursive formations do not necessarily reflect those of their Latino users. This study provides a look at only a very small subset of the Latino population, but even this small study suggests some ways in which library services might be made more pluralistic. The Latino students participating in this study had reasonably consistent reactions to the thought of "the library" as an institution and ideas about what people ought to be doing at and with libraries. Students were com- 
fortable when they knew how to use the library and when they were aware of expected behaviors, which reflected an acceptance, conscious or unconscious, of the prevailing cultural hegemony. This acceptance is contingent upon students being presented with library norms but also upon their ability to operate biculturally, transitioning between cultural and societal expectations.

The descriptions of their library experiences suggest that the library plays an ambiguous role in the lives of these Latino students. Their stories revealed that their attitudes toward libraries were more complex than we originally anticipated. Additional studies which look at class, nationality, and linguistic differences could add to the body of research regarding library service to Latinos and other ethnic populations in the United States, as well as considering the perspectives of the non-Latino user population. Research of this type may help build the phenomenological bases for creating and structuring responsive library services. This article has identified a few of the different ways that libraries are viewed, as both institutions and places, by a particular Latino population. Libraries can use these reactions to gain insight and understanding into policies and procedures, and into how to improve them. The experiences of these students, as well as of other patrons, can be used to help recreate the library as a more pluralistic space.

\section{REFERENCES}

1. Ditzion, Sidney H. Arsenals of a Democratic Culture: A Social History of the American Public Library Movement in New England and the Middle States from 1850 to 1900. Chicago: American Library Association, 1947.

2. Harris, Michael H. "State, Class, and Cultural Reproduction: Towards a Theory of Library Service in the United States." In Advances in Librarianship, edited by Wesley Simonton, pp. 211-52. Minneapolis: University of Minnesota Press, 1986.

3. Bureau of Labor Statistics. "Employed Persons by Detailed Occupation, Sex, Race, and Hispanic or Latino Ethnicity." Employment and Earnings 53, no. 1 (January 2006): 218-23.

4. American FactFinder. United States: General Demographic Characteristics, 2004. http://factfinder .census.gov/.

5. Luévano-Molina, Susan. "Mexican/Latino Immigrants and the Santa Ana Public Library: An Urban Ethnography." In Immigrant Politics and the Public Library, edited by Susan Luévano-Molina, pp. 43-63. Westport, CT: Greenwood, 2001.

6. Lears, T. J. Jackson. "The Concept of Cultural Hegemony: Problems and Possibilities." The American Historical Review 90, no. 3 (June 1985): 567-93.

7. Hynes, David. "Michel Foucault's Archeology of Knowledge." Codgito 4 (1996). http:// www.mun.ca/phil/codgito/vol4/v4doc1.html.

8. Scott, Alison M. "Romance in the Stacks; or, Popular Fiction Imperiled." In Scorned Literature: Essays on the History and Criticism of Popular Mass-Produced Fiction in America, edited by Lydia Cushman Schurman and Diedre Johnson, pp. 213-25. Westport, CT: Greenwood, 2002. 
9. Kracker, Jacqueline, and Polio, Howard R. "The Experience of Libraries across Time: Thematic Analysis of Undergraduate Recollections of Library Experiences.” Journal of the American Society for Information Science and Technology 54, no. 12 (October 2003): 1104-16.

10. Haro, Robert P. "How Mexican Americans View Libraries." Wilson Library Bulletin 44, no. 7 (March 1970): 736-42.

11. Haro, Roberto Peter, and Cabello-Argandoña, Robert. 1972. A Systems Analysis of Southwestern Spanish Speaking Users and Nonusers of Library and Information Services Developing Criteria to Design an Optimal Model Concept: Final Report. Washington, DC: National Education Resources Institute, Inc., 1972. ERIC Document Reproduction Service, ED006173.

12. Haro, Robert P. Developing Library and Information Services for Americans of Hispanic Origin. Metuchen, NJ: Scarecrow, 1981.

13. Güereña, Salvador. "Library Survey Analysis and the Spanish Speaking in California." In Biblio-Politica: Chicano Perspectives on Library Service in the United States, edited by Francisco Garcia-Ayvens and Richard F. Chabran, pp. 71-88. Berkeley: University of California Chicano Studies Library Publications Unit, 1984.

14. Barringer, Felicity. "Census Shows Profound Change in Racial Makeup of the Nation." New York Times, 11 March 1991, A1, B8.

15. Ayala, Reynaldo, and Ayala, Marta Stiefel. Report Card on Public Library Services to the Latino Community. Calexico, CA: REFORMA, 1994.

16. Weisberg, Herbert F.; Krosnick, Jon A.; and Bowen, Bruce D. An Introduction to Survey Research, Polling, and Data Analysis. 3rd ed. Thousand Oaks, CA: Sage Publications, 1996.

17. Whitmire, Ethelene. "Cultural Diversity and Undergraduates' Academic Library Use." Journal of Academic Librarianship 29, no. 3 (May 2003): 148-61.

18. Whitmire, Ethelene. "The Campus Racial Climate and Undergraduates' Perceptions of the Academic Library." Portal: Libraries and the Academy 4, no. 3 (2004): 363-78.

19. Cabello-Argandoña, Roberto. "Library Services to the Spanish Speaking and Database Development." In Ethnic Collections in Libraries, ed. E. J. Josey and Marva L. DeLoach, pp. 101-18. New York: Neal-Schuman, 1983.

20. Jensen, Bruce. "The Cárcel and the Biblioteca." In The Power of Language/El poder de la palabra: Selected Papers from the Second REFORMA National Conference, ed. Lillian CastilloSpeed, pp. 83-101. Englewood, CO: Libraries Unlimited, 2001.

21. Güereña, Salvador. "Library Survey Analysis and the Spanish Speaking in California." In Biblio-Politica: Chicano Perspectives on Library Service in the United States, edited by Francisco Garcia-Ayvens and Richard F. Chabran, pp. 71-88. Berkeley: University of California, Chicano Studies Library Publications Unit, 1984.

22. Pucci, Sandra. "Supporting Spanish-Language Literacy: Latino Children and School and Community Libraries." In Literacy, Access, and Libraries among the Language Minority Population, edited by Rebecca Constantino, pp. 17-52. Lanham, MD: Scarecrow, 1998.

23. Alira, Camila, and Archibeque, Orlando. Serving Latino Communities: A How-to-Do-It Manual for Librarians. New York: Neal-Schuman, 1998.

24. United States Census Bureau. "College Enrollment by Selected Characteristics: 1990-2001." In Statistical Abstract of the United States, 2004-2005, pp. 133-82. Washington, DC: Government Printing Office, 2004. http://www.census.gov/prod/2004pubs/04statab/ educ.pdf.

25. United States Census Bureau. "Educational Attainment by Selected Characteristic." In Statistical Abstract of the United States, 2003, pp. 145-94. Washington, DC: Government Printing Office, 2003. http://www.census.gov/prod/2004pubs/03statab/educ.pdf.

26. Nicolau, Siobban, and Valdivieso, Rafael. "Spanish Language Shift: Educational Implications." In Language Loyalties: A Source Book on the Official English Controversy, edited by James Crawford, pp. 317-22. Chicago: University of Chicago Press, 1992. 